\title{
Science in support of coastal ocean forecasting-part 1
}

\author{
Pierre De Mey $^{1}$ (D) Emil Stanev $^{2} \cdot$ Vassiliki H. Kourafalou $^{3}$
}

Received: 15 March 2017 / Accepted: 21 March 2017 / Published online: 7 April 2017

(C) Springer-Verlag Berlin Heidelberg 2017

\section{Introduction}

In parallel to the ever increasing activities and population in the coastal regions, and to the critical growth of the associated stresses on the coastal environment, the need for monitoring and forecasting of currents and marine parameters in the coastal and shelf seas is becoming more pressing (e.g. De Mey et al. 2009; De Mey and Kourafalou 2014). Largescale ocean modeling, observational, and forecasting projects provide products which are available everywhere, but the relevance of those products in coastal regions is often found inadequate (De Mey and Proctor 2009). Because of the smaller-scale, higher-frequency, coupled coastal dynamical, and biogeochemical processes found in coastal regions, and because of the presence of the coastline, shelves, coastal rivers, and other unique elements, specific coastal modeling, observational, and forecasting strategies have to be designed, within a general paradigm of integration between large-scale, regional, and coastal ocean forecasting systems (e.g., Stanev et al. 2016). Science has to be advanced to that end, as a community effort: this is what the Coastal Ocean and Shelf Seas Task Team (COSS-TT) aims to do within GODAE

Responsible Editor: Jörg-Olaf Wolff

Pierre De Mey

pierre.de-mey@legos.obs-mip.fr

1 LEGOS, Laboratoire d'Etudes en Géophysique et Océanographie Spatiales, Toulouse, France

2 HZG, Helmholtz-Zentrum Geesthacht, Geesthacht, Germany

3 Rosenstiel School of Marine and Atmospheric Sciences, University of Miami, Miami, FL, USA
Ocean View (GOV, www.godae-oceanview.org), as illustrated in Kourafalou et al. (2015a, b).

Five successful international COSS-TT meetings so far helped define priority areas where science is needed for the development of Coastal Ocean Forecasting Systems: (a) monitoring of physical and biogeochemical parameters in coastal regions (including active links with the coastal altimetry community); (b) development of fine-scale coastal ocean models; (c) integration topics: downscaling the ocean estimation problem from large-scale to coastalscale models, data and forcings, coastal data assimilation and prediction, and consistent validation metrics; (d) coastal-scale atmosphere-wave-ocean couplings; (e) ecosystem response to the physical drivers; (f) probabilistic approaches and risk assessment in the coastal ocean, including extreme events.

Papers in this collection have been gathered in themes which cut across those boundaries: (1) coastal monitoring and array design, (2) coastal modeling, integration, and model-data synergy, (3) coastal data assimilation and prediction, and (4) coastal applications. A summary of all contributions is included below.

\section{Theme 1: coastal monitoring and array design}

When designing an operational monitoring and forecasting system, assessing the contributions of available observations at impacting the quality of estimates is essential. Grayek et al. (2015) analyze the performance of an observing system in the Black Sea composed of satellite altimetry, satellite radiometer sea surface temperature (SST), and Argo floats. Numerical model outputs are also used. Both adequacies and limitations of the existing system are identified, in particular concerning the current Black Sea Argo network: the current float number 
(10) appears adequate, but precise Argo pressure measurements seem very important to resolve the very sharp stratification in the upper layers.

Lamouroux et al. (2016) describe the quantitative benefit of using environmental observations from sensors attached to fishing nets provided by the French RECOPESCA program when monitoring $3 \mathrm{D}$ coastal ocean variables in the Bay of Biscay and the English Channel. They use a stochastic methodology to evaluate the objective performance of a network design at detecting prior errors without running a fully assimilative system. They demonstrate the capabilities of this approach to describe a wide range of processes in the coastal ocean, as well as for detecting the main model uncertainties. They also demonstrate that the proposed method can be used to design new in situ observation networks.

\section{Theme 2: coastal modeling, integration, and model-data synergy}

The performance of regional/coastal operational systems, as well as the improvement of knowledge about the processes in the coastal ocean, is dependent on how the interaction between watersheds, estuaries, and ocean is accounted for the numerical models. Campuzano et al. (2016) present an original methodology for integrating the water cycle from the rainwater to the open ocean by using an offline coupling technique. With their modeling application to the Tagus River and validation of model against observations, they demonstrate an improvement of the model skill to simulate the fresh water inputs into a regional ocean model.

A 2-km horizontal resolution ocean circulation model is developed by Durski et al. (2015) for the coastal region along the US Pacific Northwest coast and is validated against satellite measurements of SST and sea surface height (SSH), observations of surface currents by high frequency (HF) radars, mooring temperature time series, and glider temperature and salinity sections. The numerical simulations demonstrate reasonable integrated characteristics of the annual cycle, transitions between seasonal states forced by different winds, as well as interannual variability caused by ENSO.

Le Hénaff and Kourafalou (2016) use a high-resolution regional numerical model of the Gulf of Mexico to describe and explain the offshore pathways of Mississippi River waters, which are influenced by the deep basin mesoscale circulation and can travel hundreds of kilometers across the Gulf, reaching and impacting South Florida coral reefs. The model is complemented by observations from the Pulley Ridge coral reef region on the Southwest Florida Shelf. The model simulation is aimed to be realistic, as it assimilates SST and altimetry, implements details in river plume physics, and uses highfrequency forcings. Together, model and data are employed to help elucidate and quantify processes impacting the connectivity between southern Florida reefs and the Mississippi Delta, as well as the local connectivity between neighboring reefs.

Lima et al. (2016) assess the structure and variability of the Brazil Current in 2004-2012 from multi-year monitoring by a high-density XBT transect and from results of three numerical models with data assimilation: HYCOM-NCODA, GLORYS, and FOAM, with resolution ranging between $1 / 4^{\circ}$ and $1 / 12^{\circ}$. Qualitative and quantitative assessments of models show a fair agreement with data in the observed region. However, models are also able to pinpoint deficiencies in the monitoring system: they show that the XBT array misses a significant fraction of the coastal transport between the coastline and the western edge of the monitoring transect.

Sakamoto et al. (2016) have developed a coastal model of the Seto Inland Sea with a horizontal resolution of $\sim 2 \mathrm{~km}$. They demonstrate that the use of tidal mixing parameterization improves the simulated frontal structure and that the model shows a realistic variability in the temporal range from several days to seasons, even without data assimilation. The model is prepared as a support of the monitoring and forecasting system operated by the Japan Meteorological Agency.

\section{Theme 3: coastal data assimilation and prediction}

Da Rocha Fragoso et al. (2016) describe a comprehensive regional data assimilation system with mostly coastal focus off the coast of Brazil. The 4D-Var schemes assimilate satellite SST, satellite altimetry, and in situ data from a regional OOS - the Santos Basin Ocean Observing System ("Project Azul"). The results illustrate the improvement in the skill of ocean hindcasts in the studied region brought by the 4D-Var assimilation.

Han et al. (2016) aggregate information from several data assimilation systems to produce a better estimate of the volume transport through the straits of the East Japan Sea. This is done by means of several regression techniques within the Multi-Model Ensemble methodology. It is shown that the method is capable of outperforming all single models by reducing uncertainties.

Kwon et al. (2016) demonstrate how the accuracy of ocean predictions in the Yellow and East China Sea can be increased by assimilating satellite-borne SST using an Ensemble Kalman Filter (EnKF). They compare the assimilation results with and without the stochastically perturbed model parameters, such as eddy viscosity, bottom drag coefficient and light attenuation depth, and atmospheric forcing. The stochastic representation of the model errors by the perturbations of the model parameters and atmospheric forcing enhances the performance of the ensemble modeling system in the Yellow and East China Sea.

A multi-scale three-dimensional variational scheme is implemented by Li et al. (2015) to improve the effectiveness of 
the assimilation of both very sparse and high-resolution observations into models with resolutions down to $1 \mathrm{~km}$. The cost function consists of two components for large and small scales. This scheme is applied to coastal ocean data, and a number of Observing System Simulation Experiments (OSSEs) have been performed, illustrating the advantages of the proposed method over conventional 3D-VAR.

The data assimilation system of the South China Sea has been presented by Xie et al. (2015). This system uses the hybrid Ocean Model (HYCOM) with tidal and atmospheric forcing and assimilates along-track altimetry data with the Ensemble Optimal Interpolation (EnOI). Simulations with different forcing switched on and off and without data assimilation suggest that the transient characteristics of currents are due to the atmospheric forcing, while tidal forcing tends to reduce the strength of the South China Sea warm current.

\section{Theme 4: coastal applications}

Brenner (2015) concentrates on specific questions within the environmental impact assessment of the drilling and exploitation of new oil wells in the Eastern Mediterranean Sea. Oil spill modeling is carried out with the MEDSLIK model, taking into account advection, dispersion, and physiochemical weathering of the surface slick. In the studied scenarios, the model is driven by downscaled ocean reanalysis data and is forced by atmospheric analyses. In addition to the downscaled ocean data, the quality of the wind estimate is found to be critical in reproducing both the oil evaporation and the slick motion toward the coast.

Zodiatis et al. (2015) assess the impact of sea surface currents on surface waves, and in particular on wave energy potential. The study is conducted over a coastal area of the Eastern Mediterranean Sea in a downscaled domain from the CMEMS (Copernicus Marine Environment Monitoring Service) ocean estimates. The impact of ocean currents on the wave potential is found to be critical in wave models, enhancing the need to include them in renewable energy studies, in addition to the usual meteo-ocean variables.

Acknowledgements As editors of this Topical Collection and coorganizers of the COSS Task Team meetings where these works were presented, we would like to express our gratitude to the GODAE OceanView Project Office, to all co-authors, to the hosts of the meetings, and to the very active and productive COSS community for their outstanding participation in the meetings.

\section{References}

Brenner S (2015) Oil spill modeling in the southeastern Mediterranean Sea in support of accelerated offshore oil and gas exploration. Ocean Dyn 65(12):1685-1697. doi:10.1007/s10236-015-0902-2
Campuzano F, Brito D, Juliano M, Fernandes R, de Pablo H, Neves R (2016) Coupling watersheds, estuaries and regional ocean through numerical modelling for western Iberia: a novel methodology. Ocean Dyn 66(12):1745-1756. doi:10.1007/s10236-016-1005-4

De Mey P, Kourafalou VH (2014) The GODAE OceanView Coastal Ocean and shelf seas Task Team. In: Djavidnia S, Cheung V, Ott M, Seeyave S (eds) Oceans and society: blue planet. Cambridge Scholars Publishing, Newcastle upon Tyne ISBN: 978-1-44385639-3

De Mey P, Proctor R (2009) Assessing the value of GODAE products in coastal and shelf seas. Editorial, special issue of ocean dynamics, 2007 GODAE coastal and shelf seas workshop, Liverpool, UK. Ocean Dyn 59(1):1-2. doi:10.1007/s10236-008-0175-0

De Mey P, Craig P, Davidson F, Edwards CA, Ishikawa Y, Kindle JC, Proctor R, Thompson KR, Zhu J, the GODAE Coastal and Shelf Seas Working Group (CSSWG) community (2009) Applications in coastal modelling and forecasting. Ocean Mag 22(3):198-205

Durski SM, Kurapov AL, Allen JS, Kosro PM, Egbert GD, Shearman RK, Barth JA (2015) Ocean Dyn 65(12):1643-1663. doi:10.1007/ s10236-015-0891-1

Grayek S, Stanev EV, Schulz-Stellenfleth (2015) Assessment of the Black Sea observing system. A focus on 2005-2012 Argo campaigns. Ocean Dyn 65(12):1665-1684. doi:10.1007/s10236-015-0889-8

Han S, Hirose N, Usui N, Miyazawa Y (2016) Multi-model ensemble estimation of volume transport through the straits of the East/Japan Sea. Ocean Dyn 66(1):59-76. doi:10.1007/s10236-015-0896-9

Kourafalou VH, De Mey P, Le Hénaff M, Charria G, Edwards CA, He R, Herzfeld M, Pasqual A, Stanev E, Tintoré J, Usui N, Van Der Westhuysen A, Wilkin J, Zhu X (2015a) Coastal Ocean forecasting: system integration and validation. J Operat Ocean 8(sup1):s127s146. doi:10.1080/1755876X.2015.1022336

Kourafalou VH, De Mey P, Staneva J, Ayoub N, Barth A, Chao Y, Cirano M, Fiechter J, Herzfeld M, Kurapov A, Moore AM, Oddo P, Pullen J, van der Westhuysen A, Weisberg RH (2015b) Coastal Ocean forecasting: science foundation and user benefits. J Operat Ocean 8(sup1):s147-s167. doi:10.1080/1755876X.2015.1022348

Kwon KM, Choi B-J, Lee S-H, Kim YH, Seo G-H, Cho Y-K (2016) Effect of model error representation in the Yellow and East China Sea modeling system based on the ensemble Kalman filter. Ocean Dyn 66(2):263-283. doi:10.1007/s10236-015-0909-8

Lamouroux J, Charria G, De Mey P, Raynaud S, Heyraud C, Craneguy P, Dumas F, Le Hénaff M (2016) Objective assessment of the contribution of the RECOPESCA network to the monitoring of 3D coastal ocean variables in the Bay of Biscay and the English Channel. Ocean Dyn 66(4):567-588. doi:10.1007/s10236-016-0938-y

Le Hénaff M, Kourafalou VH (2016) Mississippi waters reaching South Florida reefs under no flood conditions: synthesis of observing and modeling system findings. Ocean Dyn 66(3):435-459. doi:10.1007/ s10236-016-0932-4

Li Z, McWilliams JC, Ide K, Farrara JD (2015) Coastal ocean data assimilation using a multi-scale three-dimensional variational scheme. Ocean Dyn 65(7):1001-1015. doi:10.1007/s10236-015-0850-x

Lima MO, Cirano M, Mata MM, Goes M, Goni G, Baringer M (2016) An assessment of the Brazil current baroclinic structure and variability near $22^{\circ} \mathrm{S}$ in Distinct Ocean forecasting and analysis systems. Ocean Dyn 66(6):893-916. doi:10.1007/s10236-016-0959-6

da Rocha Fragoso M, de Carvalho GV, Soares FLM, Faller DG, de Freitas Assad LP, Toste R, Barbosa Sancho LM, Nóbrega Passos E, Stefoni Böck C, Reis B, Landau L, Arango HG, Moore AM (2016) A 4Dvariational ocean data assimilation application for Santos Basin, Brazil. Ocean Dyn 66(3):419-434. doi:10.1007/s10236-016-0931-5

Sakamoto K, Yamanaka G, Tsujino H, Nakano H, Urakawa S, Usui N, Hirabara M, Ogawa K (2016) Development of an operational coastal model of the Seto Inland Sea, Japan. Ocean Dyn 66(1):77-97. doi: 10.1007/s10236-015-0908-9 
Stanev EV, Schulz-Stellenfleth J, Staneva J, Grayek S, Grashorn S, Behrens A, Koch W, Pein J (2016) Ocean forecasting for the German bight: from regional to coastal scales. Ocean Sci 12(5): 1105-1136. doi:10.5194/os-12-1105-2016

Xie J, Zhu J, Bertino L, Counillon F (2015) Analysis of the northern South China Sea counter-wind current in winter using a data assimilation model. Ocean Dyn 65(4):523-538. doi:10.1007/ s10236-015-0817-y

Zodiatis G, Galanis G, Kallos G, Nikolaidis A, Kalogeri C, Liakatas A, Stylianou S (2015) The impact of sea surface currents in wave power potential modeling. Ocean Dyn 65(11):15471565. doi:10.1007/ s10236-015-0880-4 